\title{
Compact UWB antenna with T-Shaped Slots and Staircase Ground Plane for Enhanced Bandwidth
}

\author{
Shashi Kant Dargar ${ }^{1}$, Santosh Bharti ${ }^{2}$, Abha Nyati $^{3}$ \\ ${ }^{1}$ (Department of E\&C Engineering, Sir Padampat Singhania University, India) \\ ${ }^{2}$ (Department of E\&C Engineering, Sir Padampat Singhania University, India) \\ ${ }^{3}$ (Department of E\&C Engineering, Pacific University, India)
}

\begin{abstract}
In the coming years, there is great demand for high-speed data transmissions on cost effective basis. In order to achieve the same a new technology known as the Ultra WideBand (UWB) has been used. This technology has revolutionary advantages of an unlicensed service that can be used anywhere, anytime, by anyone. UWB is well known technology for its use in communications and radar applications, unlike traditional systems; this can only operate over a specific range of frequencies. UWB devices operate by employing a series of very short electrical pulses that result in very wideband transmission bandwidths. In addition, UWB signals can run at high speed and low input power. Hence, there is a need to implement characteristics while designing small antennas. The purpose of this work is to propose an inexpensive, light-weight, compact and portable new type ultra-wideband antenna for pulsed applications. The general approach to this design is to feed the antenna by a $50 \mathrm{ohm}$ Sub Miniature A (SMA) cable through a micro strip line. Firstly the model is simulated using AnsoftHigh Frequency Structure Simulation(HFSS) software. This Ansoft HFSS software is mainly used for antenna analysis and design. The software is based on The Method of Moments (MoM) algorithm and therefore quantitative results can be obtained. In an attempt to achieve the best overall performance, experimental simulation results are continually assessed using different parameters so as to get the best results. This was followed by constructing the prototype. The final prototype fabricated showed comparable results of the simulation.
\end{abstract}

Keywords - Ultra Wideband, Microstrip Antenna, Partial Ground Plane, Monopole antenna,

\section{Introduction}

In recent years significant contributions have been made in the field of antenna design. The UWB technology has experienced many significant developments in recent years. Owing to its low cost, low profile, ease of fabrication and wide bandwidth, the printed planar structure appears to be the most promising feature for wideband applications. Subsequently, various planar antennas have been proposed and investigated because of their advantages in terms of size, band width and impedance matching. A great deal of research is going on for finding new antenna design and size to achieve the better bandwidth for UWB antenna. In numerous applications including digital communications and radar \& sonar engineering etc., the main motive is to reduce the size of the device without affecting the performance and enhancing the bandwidth. Now a day's ultra wideband technology being used in radar and sensing applications right through to high band width communications. Furthermore ultra wide band, can be used in both commercial and military applications.

\section{BACKGROUND}

Seok H. Choi,1 Jong K. Park,1 Sun K. Kim,1 and Jae Y. Park in (2004)- They propose a UWB antenna for UWB designed to operate from 3.2 to $12 \mathrm{GHz}$. It consists of a rectangular patch with two steps, a single slot on the patch, and a partial ground plane [1]. Mohamed A. Hassanien and Ehab K. I. Hamad in their paper explained the performance of a rectangular micro strip patch antenna fed by micro strip line for operation in ultra-wide band applications. It consists of a rectangular patch with U-shaped slot on one side of the substrate and a finite ground plane on the other side. The U-shaped slot and the finite ground plane are used to achieve an excellent impedance matching to increase the bandwidth. The proposed antenna is designed and optimized based on extensive 3D EM simulation studies. The proposed antenna is designed to operate over a frequency range from 3.6 to $15 \mathrm{GHz}$ [2].

The good matching of antenna depends on the matching between the feeding network and the radiation element, as well as the inherent matching of feeding network. In this work, the PIFA antenna design with good impedance matching firstly, and the differential-feeding technique is employed to achieve UWB performance. A prototype of this UWB antenna is fabricated and measured. The experimental results indicate that the impedance bandwidth $(\mathrm{SWR}<2)$ of the PIFA is about $93.1 \%(3.1 \mathrm{GHz} \sim 8.5 \mathrm{GHz})$. In addition, the symmetric and stable radiation patterns are observed within the wide band, demonstrating the validity of the design strategies and the potential application of this UWB PIFA antenna [3]. M. Ojaroudi, Sh. Yazdanifard, N. Ojaroudi, and M. Naser- 
Moghaddasiin designed a novel printed monopole antenna for ultra wideband applications. The antenna consists of a square radiating patch with an inverted Tshaped slot and a ground plane with an inverted $\mathrm{T}$ shaped conductor backed plane, This could be achieved by cutting a modified inverted Tshaped slot with variable dimensions on the radiating patch and also by inserting an inverted $\mathrm{T}$ shaped conductor-backed plane, additional resonances are excited and hence much wider impedance bandwidth can be produced, especially at the higher bands. The designed antenna has a small size of $12 \mathrm{~mm} \times 18 \mathrm{~mm}$. Simulated and experimental results obtained for this antenna show that it exhibits good radiation behavior within the UWB frequency range [5]. Ahmed AlShaheen and Hussain Al Rizzo have presented a miniaturized, Ultra Wide Band (UWB) elliptical slot antenna with a circular stub as a tuning element printed on a FR4 substrate with a dielectric constant of 4.4 operating in the frequency range from $2 \mathrm{GHz}$ up to $14 \mathrm{GHz}$ over which the return loss is below $-10 \mathrm{~dB}$. The antenna is intended to operate in a system designed to assist the visually impaired in indoor navigation utilizing UWB technology. The concentric circular tuning stub is introduced in order to tune which improves coupling of the higher-order modes. M. Ojaroudi, Sh. Yazdanifard, N. Ojaroudi, and R. A. Sadeghzadehin proposed a novel printed monopole antenna with constant gain over a wide bandwidth for ultra wideband applications with desired notch band characteristics. They proposed antenna consists of a square ring radiating patch with a pair of $\mathrm{T}$ shaped strips protruded inside the square ring and a coupled $\mathrm{T}$ shaped strip and a ground plane with a protruded strip, which provides a wide usable fractional bandwidth of more than $130 \%$ (3.07-14.6 GHz). By using the square-ring radiating patch with a pair of Tshaped strips protruded inside it, the frequency band stop performance is generated, and we can control its characteristics such as band-notch frequency and its bandwidth by electromagnetically adjusting coupling between a pair of Tshaped strips protruded inside the square ring. The designed antenna has a small size of $12 \mathrm{~mm} \times 18 \mathrm{~mm}$, or about $0.15 \lambda-0.25 \lambda$ at $4.2 \mathrm{GHz}$, while showing the band-rejection performance in the frequency band of 5.05-5.95 GHz. [8].

The outcomes of the literature survey conclude that micro strip patch antennas have better performance. Different type of feeding methods and the various shapes of patch are used to improve the performance. Simulation of micro strip patch antenna can be carried out on non-real time environment only. The different software can used to simulate the design of antenna like CST Microwave studio, Ansoft HFSS (High Frequency Structure Simulation). For real time applications in order to implement the hardware antennas are required. Hence the required antenna has also been fabricated in order to simulate the results.

\section{IMPLEMENTATION}

As the name implies ultra wide band technology, is a form of transmission that occupies a very wide bandwidth. Typically this will be many Giga hertz, and it is this aspect that enables it to carry data rates of Gigabits per second. Despite the single named use for the ultra wideband (UWB) transmissions, there are two very different technologies being developed. The one is Carrier free direct sequence ultra wideband technology and MBOFDM and the other is Multi-Band OFDM ultra wideband technology. Ground plane, radiating elements, SMA connector is installed such that its base is shorted with the ground plane copper sheet and its inner conductor is shorted to the radiating element of the antenna, or the longer of the two T shaped rods.

High Frequency Structure Simulation (HFSS) Software is used as an evaluation and design tool for the majority of the work carried out in the work. etc. Once a mesh is created, basis functions are defined for each tetrahedral. The basis function, $\mathrm{W}_{\mathrm{n}}$ define the conditions between the nodal locations in the overall mesh of tetrahedral based on the problem inputs. The basis functions are then multiplied by the field Equation (1), derived from Maxwell's equation.

$$
\nabla \times\left(\frac{1}{\mu} \times \overline{\mathrm{E}}\right)-k_{0}^{2} \varepsilon_{,}, \overline{\mathrm{E}}=0
$$

The result is then integrated over the volume of the tetrahedron

$$
\int_{v}\left[W_{n} \nabla \times\left(\frac{1}{\mu_{r}} \times \overline{\mathrm{E}}\right)-k_{0}^{2} \varepsilon_{e} \overline{\mathrm{E}}\right] d V=0
$$

This is then rewritten using the Green's and divergence theorems and is then set equal to the excitation/boundary terms

$$
\int_{v}\left[\nabla \times W_{n} \cdot\left(\frac{1}{\mu_{r}} \times \overline{\mathrm{E}}\right)-k_{0}^{2} \varepsilon_{\mathrm{B}} \overline{\mathrm{E}}\right] d V=\int_{s} \text { Boundary terms }
$$

The electric-field vector is then written as a summation of unknowns; $\mathrm{X}_{\mathrm{m}}$, multiplied by the same basis functions used in generating the initial series of equations

$\overline{\mathrm{E}}=\sum_{m=1}^{N} X_{m} W_{m}$

The resulting equations allow the solution of the unknowns, $\mathrm{Xm}$, to find the electric-fields. The general form of the expression is as follows: 
$\sum_{m=1}^{N} X_{m}\left(\int_{v}\left[\left(\nabla \times W_{n}\right) \cdot\left(\frac{1}{\mu_{r}} \times W_{m}\right)-k_{0}^{2} \varepsilon_{r} W_{n} W_{m}\right] d v\right)=\int_{s}$ (Boundary terms) $d s$

Once the values have been calculated using the solver, a second adaptive pass occurs and HFSS compares the Sparameters to the previous mesh-based solution. This process is repeated and the difference between the two solutions is calculated. This process is continued until the solution has converged to an acceptable difference, usually $2 \%$ or less, this being defined by the user. HFSS was mainly used in this thesis for evaluating S parameters, radiation characteristics and field distributions for both antennas and passive components.

Design Specifications: Frequency of operation $\left(f_{0}\right)$ resonant frequency of the antenna must be selected appropriately. The UWB uses the frequency range from 3.1-10.6GHz. Hence the antenna designed must be able to operate in this frequency range. The resonant frequency selected for the design is $6.85 \mathrm{GHz}$. The dielectric material selected for the design is Flame Retardant 4 (FR4) which has a dielectric constant of 4.4.

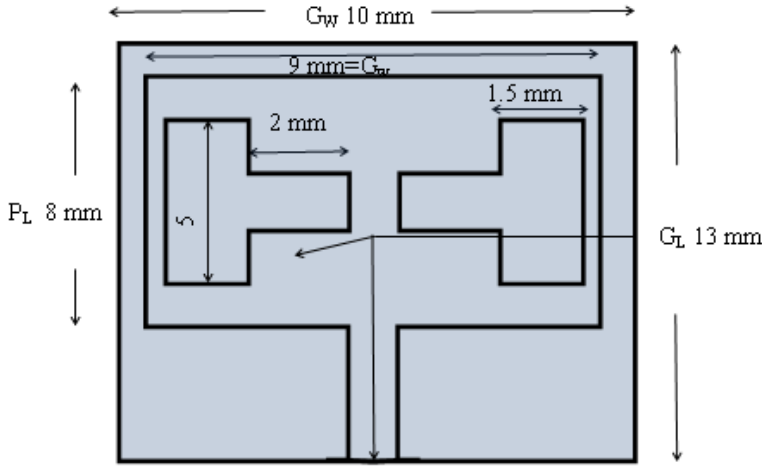

Fig. Front and back end

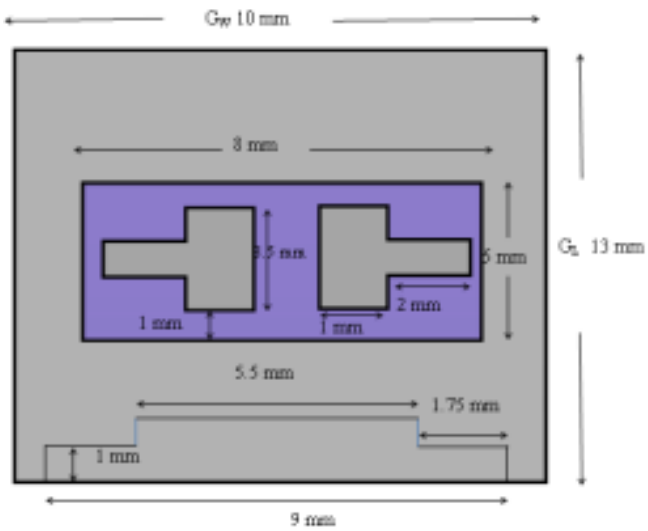

A substrate with a high dielectric constant has been selected since it reduces the dimensions of the antenna. Height of dielectric substrate (h): For the micro strip patch antenna to be used in UWB, it is essential that the antenna is not bulky. Hence, the height of the dielectric substrate is selected as $0.85 \mathrm{~mm}$. In this design, the dimensions of the designed antenna, including the substrate $\mathrm{W}^{*} \mathrm{~L}$ are $13 \mathrm{~mm} * 10 \mathrm{~mm}$. Simulating structures in HFSS, Models in HFSS are created relatively easily, by the user or imported in a DXF file format. The basic structure consists of a rectangular patch, a feed line and a ground plane.

\section{RESUlTS AND DisCUSSIONS}

Between $3.1 \mathrm{GHz}$ and $10.6 \mathrm{GHz}$ simulated return loss curve was below 2 VSWR $(\sim 10 \mathrm{~dB})$. As we know that the return loss is the most important parameter which has to be taken into account. Simulation results are shown for the frequency $6 \mathrm{GHz}$ for the designed antenna.

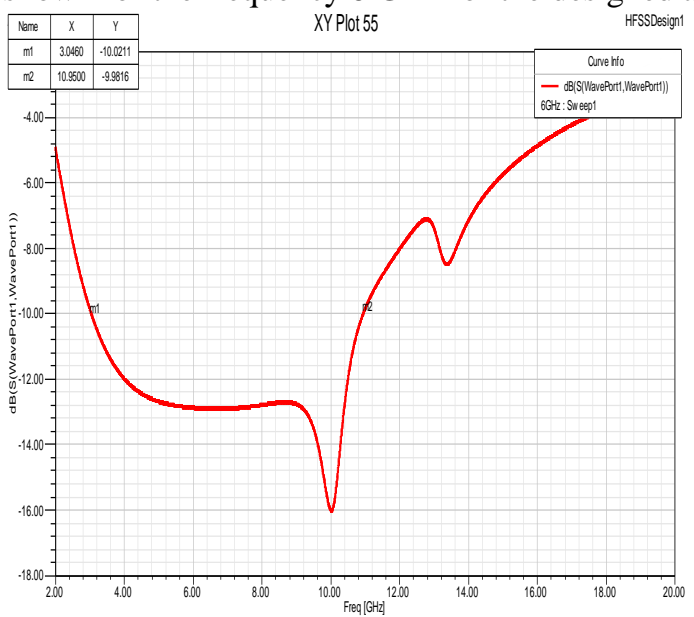

Fig. Simulated Return loss of designed antenna

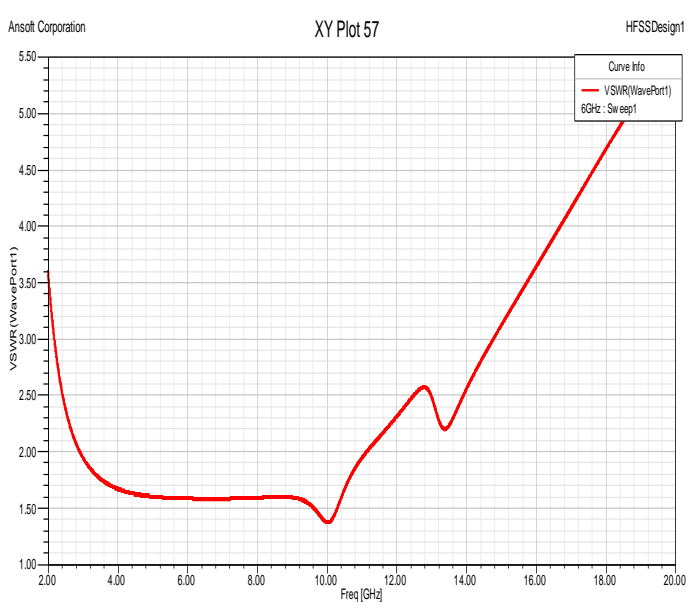

Fig. Simulated VSWR of designed antenna 

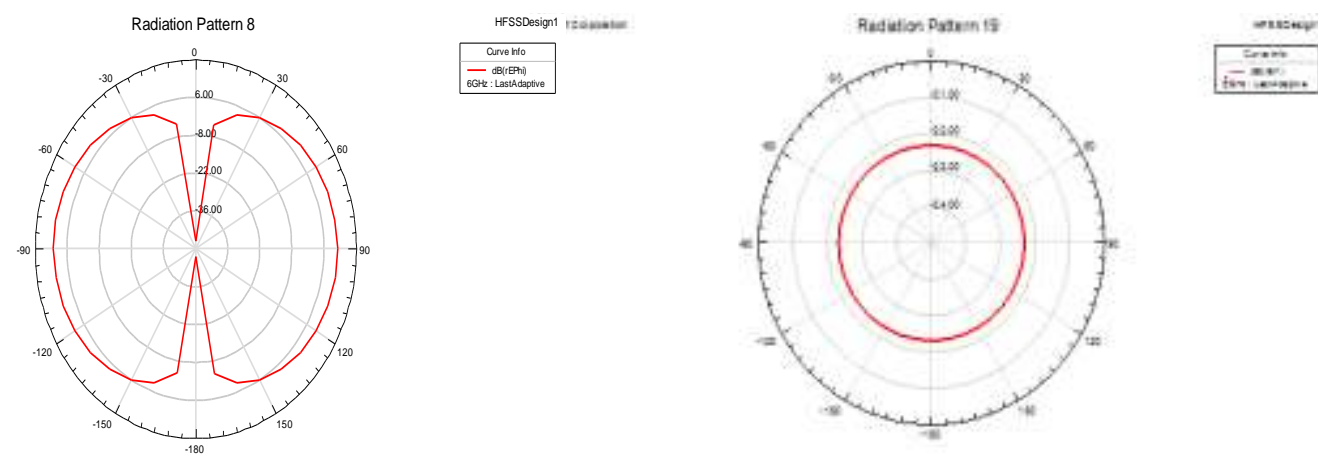

Fig. 6.7: Simulated results (a) E plane (b) $\mathrm{H}$ plane radiation pattern of designed antenna at $6 \mathrm{GHz}$.
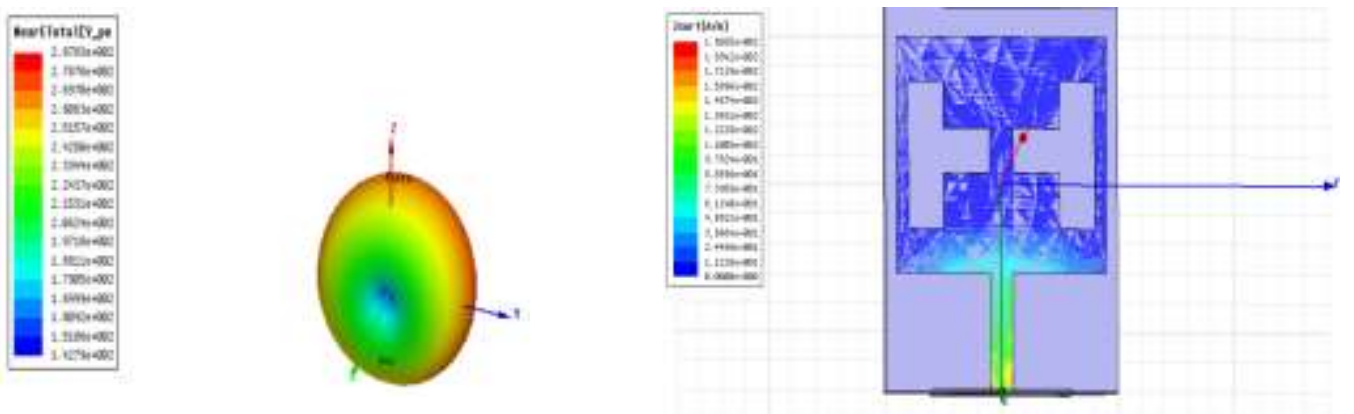

Fig. 6.5 Simulated 3D radiation pattern at $6 \mathrm{GHz}$

Fig. Surface current distributions at $6 \mathrm{GHz}$ frequency

\section{CONCLUSION AND FUTURE WORK}

This work proposed a Small Micro Strip UWB antenna with Two T Shaped Slots and staircase ground plane with two T shaped strips antenna. This system is mainly used for UWB technology based applications. This antenna has been successfully developed after numerous modeling and simulations on AnsoftHFSS (High Frequency Structures Simulation) software to get the best combination of the parameters for overall performance. The objective was achieved after getting good results from the simulated and measured parameters. A fair comparison is presented with the other discussed antennas based on the popular micro strip antenna parameters like radiation patterns, return loss and size etc.

Microstrip antenna is simulated in AnsoftHFSS software for UWB frequency band. The antenna performance lies in the UWB frequency band. Therefore the antenna is fabricated through the lithography process. Though it is difficult to fabricate the designed antenna simulated in the AnsoftHFSS due to its small size, efforts have been made to fabricate the same and it is a matter of achievement that the simulated results have been achieved even in fabrication. The designed antenna is further tested and the measured results have shown that the antenna is working in the real time environments. with Return loss $(-10 \mathrm{~dB})$, VSWR $(<2)$ and Omni directional radiation patterns the size of the antenna $(13 \mathrm{~mm} \times 10 \mathrm{~mm})$ is smaller than others discussed antennas required for UWB frequency band $(3.1 \mathrm{GHz}-10.6 \mathrm{GHz})$.

\begin{tabular}{|c|c|c|}
\hline S. No. & Parameter & Value \\
\hline 1 & Bandwidth & $2.9 \mathrm{GHz} .-10.504 \mathrm{GHz}$ \\
\hline 2 & VSWR & $\leq 2$ \\
\hline 3 & $\mathrm{~S}_{11}$ & $\geq 10 \mathrm{~dB}$ \\
\hline 4 & Back and side lobes & Low \\
\hline
\end{tabular}

TABLE 1: ACHIEVED PARAMETERS 


\begin{tabular}{|c|c|c|c|c|c|}
\hline Parameters & $\begin{array}{l}\text { M. Ojaroudi, Sh. } \\
\text { Yazdanifard, N. } \\
\text { Ojaroudi, and } \\
\text { M.Naser }\end{array}$ & $\begin{array}{l}\text { M. Ojaroudi,Sh. } \\
\text { Yazdanifard, N. } \\
\text { Ojaroudi, and R. } \\
\text { A. Sadeghzadeh }\end{array}$ & $\begin{array}{l}\text { Mohamed A. } \\
\text { Hassanien and } \\
\text { Ehab K. I Hamad }\end{array}$ & $\begin{array}{c}\text { Lee Chai Ping } \\
\text { Chandankumar } \\
\text { Chakrabarty\&Rozanah } \\
\text { Amir Khan }\end{array}$ & $\begin{array}{l}\text { Designed } \\
\text { antenna }\end{array}$ \\
\hline Shape of patch & Square & Squaring ring & Square & Rectangular with step & Rectangular \\
\hline Shape of slot & $\begin{array}{c}\text { Inverted-T } \\
\text { shaped }\end{array}$ & $\begin{array}{l}\text { Pair of T shaped } \\
\text { strip }\end{array}$ & U shaped & Rectangular & $2 \mathrm{~T}$ shaped \\
\hline Ground plane & $\begin{array}{l}\text { Rectangular with } \\
\text { inverted } \mathrm{T}\end{array}$ & $\begin{array}{l}\text { Rectangular with } \\
\pi \text { Shaped strip }\end{array}$ & Rectangular & $\begin{array}{l}\text { Rectangular with small } \\
\text { slot }\end{array}$ & $\begin{array}{l}\text { Rectangular with } \\
\text { staircase }\end{array}$ \\
\hline $\begin{array}{l}\text { Band } \\
\text { width }\end{array}$ & $\begin{array}{c}2.19-14.1 \\
\mathrm{GHz}\end{array}$ & $\begin{array}{c}3.07-14.6 \\
\mathrm{GHz}\end{array}$ & $\begin{array}{l}3.6-15 \\
\mathrm{GHz}\end{array}$ & $\begin{array}{c}1.78-11.31 \\
\mathrm{GHz}\end{array}$ & $2.97-10.504 \mathrm{GHz}$ \\
\hline Size & $12^{\star} 18 \mathrm{~mm}^{2}$ & $12 * 18 \mathrm{~mm}^{2}$ & $30 \star 30 \mathrm{~mm}^{2}$ & $30^{\star} 25 \mathrm{~mm}^{2}$ & $13^{\star} 10 \mathrm{~mm}^{2}$ \\
\hline Material used & FR4 & FR4 & FR4 & FR4 & FR4 \\
\hline VSWR & $<2$ & $\begin{array}{c}<2 \\
(>2 \text { at } 5 \text { to } 6 \mathrm{GHz})\end{array}$ & $<2$ & $<2$ & $<2$ \\
\hline Return Loss & More than $10 \mathrm{~dB}$ & More than $10 \mathrm{~dB}$ & More than $10 \mathrm{~dB}$ & More than $10 \mathrm{~dB}$ & More than $10 \mathrm{~dB}$ \\
\hline
\end{tabular}

TABLE 2: COMPARISON TABLE OF OTHER ANTENNAS WITH DESIGNED ANTENNA

From the above table it can be concluded that the designed antenna has properties which are as per with the already designed antennas. This main attraction of our designed antenna is 'The reduced Size' and hence can be taken up for commercial purposes.

Though the designed antenna has been simulated and fabricated, there is still scope for future work in the following areas to decrease the size of the radiating element to improve bandwidth, remove the back reflector to reduce the computation time and to reduce VSWR value in order to improve the bandwidth by varying the dimension of the model.

\section{REFERENCES}

[1] Seok H. Choi,1 Jong K. Park,1 Sun K. Kim,1 and Jae Y. Park,“ A new Ultra-Wideband antenna for UWB applications” Microwave and Optical Technology Letters, Vol. 40, No. 5, March 52004 [399-401].

[2] Mohamed A. Hassanien and Ehab K. I. Hamad "Compact rectangular U-shaped slot micro strip patch antenna for UWB applications” 2010-IEEE APS, Middle East Conference on Antennas and Propagation (MECAP),Cairo, Egypt, 20.10.2010.

[3] Mei Li, Min Chen, WenquanChe, QuanXue, " UWB Planar Inverted-F Antenna (PIFA) with Differential Feeding Technique" Proceedings of 2010 IEEE International Conference on Ultra-Wideband (ICUWB) 2010.

[4] YusnitaRahayu, RazaliNgah, Tharek A. Rahman," "Various Slotted UWB Antenna Design”Sixth International Conference on Wireless and Mobile Communications 2010.

[5] M. Ojaroudi, Sh. Yazdanifard, N. Ojaroudi, and M. Naser-Moghaddasi, "Small Square Monopole Antenna With Enhanced Bandwidth by Using Inverted T-Shaped Slot and Conductor-Backed Plane"IEEE Transactions On Antennas And Propagation, Vol. 59, No. 2, February 2011.

[6] Deepak Bhatia1, Dr. Mithilesh Kumar2, and Amitabh Sharma3, "A Beam Scanning UWB Antenna System for Wireless Applications" International Journal of Electronics Engineering, 3 (1), 2011, pp. 11- 16.

[7] Natarajamani.S, S K Behera\&S K Patra, “Compact Slot Antenna For UWB Application and Band-Notch Designs" International Conference on Computational Intelligence and Communication Networks 2010.

[8] Zarreen Aijaz1\&S.C.Shrivastava, "Effect of the Different Shapes: Aperture Coupled Microstrip Slot Antenna" International Journal of Electronics Engineering, 2(1), 2010, pp. 103-105.

[9] D. Orban and G.J.K. Moernaut, "The Basics of Patch Antennas" Orban Microwave Products.

[10] AmriteshKshetrimayum Milan Singh, "Design of square patch micro strip antenna for circular polarization usgin IE3D Software"Rourkela, Orissa, India 2010.

[11] JohnnaPowell,“Antenna Design for Ultra Wideband Radio” New Mexico State University, 2001.

[12] D. C. Nascimento and J. C. da S. Lacava " "Design of Low-Cost Probe-Fed Microstrip Antennas"Technological Institute of Aeronautics Brazil.

[13] Ahmed Al Shaheen and Hussain Al-Rizzo, “An Ultra Wide Band Antenna Design for Indoor Geolocation Applications" World Applied Sciences Journal 12 (8): 1321-1326, 2011.

[14] M. Ojaroudi, Sh. Yazdanifard, N. Ojaroudi, and R. A. Sadeghzadeh, "Band-Notched Small Square-Ring Antenna With a Pair of TShaped Strips Protruded Inside the Square Ring for UWB Applications" IEEE Antennas and Wireless Propagation Letters, Vol. 10, 2011.

[15] Yusnita Rahayu, RazaliNgah, and TharekAbd.Rahman, "Current Distribution Characteristics of Various T Slotted Ultra Wideband Antenna" 978-1-4244-7092-1/10, 2010 IEEE.

[16] Wei Qin, Juan Li “A Novel Dual Frequency Notched UWB Antenna with Dual L-shape Slots” Proceedings of International Symposium on Signals, Systems and Electronics (ISSSE2010) 978-1-4244-6355-8/10 @2010 IEEE.

[17] MithileshKumar ,AnanjanBasu, Shiban K. Koul, “Active UWB Antenna”URSI International Symposium On Electromagnetic Theory 978-1-4244-5153-1/10, 2010 IEEE.

[18] SystemJyoti R. Panda, PrasaduKakumanu and Rakhesh S. Kshetrimayum, "A Wide-band Monopole Antenna in Combination with a UWB Microwave Band-pass Filter for Application in UWB Communication”Annual IEEE India Conference (INDICON)2010. 
[19] VasyJchenko, R. Dubrovka, W. De Raede, C. Parini and G. A. E. Vandenbosch, "Pulse Response Behavior of a UWB Antenna with Switchable Band-Notching Feature" Proceedings of the 5th European Conference on Antennas and Propagation (EUCAP).

[20] Mohamed A. Hassanien and Ehab K. I. Hamad, "compact rectangular U-shaped slot micro strip patch antenna for UWB applications"IEEE APS, Middle East Conference on Antennas and Propagation (MECAP),Cairo, Egypt, 20.10.2010.

[21] M. Ojaroudi, Sh. Yazdanifard, N. Ojaroudi, and M. Naser-Moghaddasi, "Small Square Monopole Antenna With Enhanced Bandwidth by Using Inverted T-Shaped Slot and Conductor-Backed Plane"IEEETransactions on Antennas And Propagation, Vol. 59, No. 2, February 2011.

[22] RezaulAzim, Ahmed ToahaMobashsher, Mohammad Tariqul Islam and Norbahiah Misran, "Compact Planar Antenna for UWB Applications" 978-1-4244-5708-3/10/\$26.00 @ 2010 IEEE.

[23] C. A. Balanis, “Antenna theory analysis and design” Wiley Interscience, USA 2005. 